\title{
MODELLING AND PREDICTION OF WATER CURRENT USING ARTIFICIAL NEURAL NETWORKS: A CASE STUDY OF THE COMMODORE CHANNEL
}

\author{
O. T. Badejo ${ }^{1,}{ }^{*}$, O. T. Jegede ${ }^{2}$, H. O. Kayode ${ }^{3}$, O. O. Durodola ${ }^{4}$ and S. O. Akintoye ${ }^{5}$ \\ $\mathbf{1 , 2 , 3 , 4 , 5}$, DEPT OF SURVEYING AND GEOINFORMATICS, UNIV. OF LAGOS, AKOKA YABA, LAGOS STATE, NIGERIA \\ E-mail addresses: ${ }^{1}$ shegunbadejo@yahoo.com, ${ }^{2}$ jegedetope330@gmail.com, \\ 3 kayodeolorunshola@yahoo.com, ${ }^{4}$ sola.bejide@yahoo.com, 5 sakintoye@unilag.edu.ng
}

\begin{abstract}
Water current modelling and prediction techniques along coastal inlets have attracted growing concern in recent years. This is largely so because water current component continues to be a major contributor to movement of sediments, tracers and pollutants, and to a whole range of offshore applications in engineering, environmental observations, exploration and oceanography. However, most research works are lacking adequate methods for developing precise prediction models along the commodore channel in Lagos State. This research work presents water current prediction using Artificial Neural Networks (ANNs). The Back Propagation (BP) technique with feed forward architecture and optimized training algorithm known as Levenbergq-Marquardt was used to develop a Neural Network Water Current Prediction model-(NNWLM) in a MATLAB programming environment. It was passed through model sensitivity analysis and afterwards tested with data from the Commodore channel (Lagos Lagoon). The result revealed prediction accuracy ranging from 0.012 to 0.045 in terms of Mean Square Error (MSE) and 0.80 to 0.83 in terms of correlation coefficient (R-value). With this high performance, the Neural network developed in this work can be used as a veritable tool for water current prediction along the Commodore channel and in extension a wide variety of coastal engineering and development, covering sediment management program: dredging, sand bypassing, beach-contingency plans, and protection of beaches vulnerable to storm erosion and monitoring and prediction of long-term water current variations in coastal inlets.
\end{abstract}

Keywords: Artificial Neural Network, Commodore Channel, Coastal Inlet, Water Current, Back Propagation.

\section{INTRODUCTION}

Water current is the rate of movement in the water, and ways to describe water current include its speed and direction [1]. It is a major dynamic element for ocean engineering. Water body current in the coastal and low-lying areas plays a significant role in the socio- economic activities of coastal area dwellers. The measurement of currents and water properties is of great importance because water current continues to be the major contributor to disposal and movement of sediments, tracers and pollutants, and to a whole range of offshore applications in engineering, environmental observations, exploration and oceanography [2, 3]. The use of Acoustic Doppler Current Profilers (ADCPs) from a moving boat is a commonly used method for measuring streamflow. Although the ADCP is a valuable tool for measuring streamflow, it is only accurate when used with appropriate techniques [4]. Marine container ships rely daily on accurate real time tide and current information to navigate safely to and from our sea ports.

According to NOAA [5], current measurement is important to shipping, commercial fishing, oil rig, recreational boating and safety. By using predicted real time and short term forecasted currents, people

* Corresponding author, tel: +234-803-863-6448 
can safely dock and undock ships, manoeuvre ships in water ways, as well as navigate them through other coastal waters. With current information, merchandise and people can arrive on schedule while collision and delayed arrivals is also brought to the barest minimum. As earlier mentioned, this research uses ANN approach to predict water current. ANN has been widely used in multivariate nonlinear time series modelling in many research areas such as in electronics, hydrology, aerospace and manufacturing engineering [6]. The analysis of the interactions between static, environmental and operational factors of the water distribution system has been provided by ANN models [7]. ANN is proficient in directly correcting the time series of multiple import variables to the output variables through the interconnected nodes using trainable weights and bias signal [8]. ANN was initially envisioned as a model of the mammalian brain [9]. According to [10], neural network technique is used to predict the storm surge with the help of four input parameters such as wind velocity, wind direction, wind pressure and harmonic analysis of tides. It is found that the network predicts better and reliable results of storm surges.

ANN is being applied to solve a wide variety of coastal/ocean engineering problems. A neural network is an information processing system modelled on the structure of human brain. A neural network possesses the ability to learn and able to memorize a large amount of various information and then to formalize it. Furthermore, the most precious quality of a neural network is its ability to provide forecasts based on the data it has processed [11].

ANN models have been used increasingly in various aspects of science and engineering, because of its ability to model both linear and nonlinear systems without the need to make any assumptions as are implicit in most traditional statistical approaches [12]. In some of the hydrologic problems, ANNs have already been successfully used for river flow prediction $[13,14]$, for rainfall-runoff process [15] for the prediction of water quality parameters [16]. In addition, ANNs are applied for prediction of evaporation [17], for rainfall-runoff forecasting [18], for prediction of flood disaster [19], and for river time series prediction [20]. In these hydrological applications, a multilayer feed-forward backpropagation algorithm was used [21, 13].

ANNs model provides the prediction by learning the characteristic pattern of the historical event or historical data. Back Propagation (BP) is the most popular supervised learning technique of ANNs. In back-propagation networks, the weights of the connections are adjusted to minimize the measure of the difference between the actual output vector of the network and the desired output vector. The BP technique with feed forward architecture and optimized training algorithm known as LevenbergMarquardt was used by [22] to develop a Neural Network Water Level Prediction model-(NNWLM) in a MATLAB programming environment. The model was tested with data from five coastal water level gauge stations. The result revealed great performance with model prediction accuracy ranging from 0.012 to 0.045 in terms of Mean Square Error (MSE) and 0.82 to 0.97 in terms of correlation coefficient (R-value).

In this study ANN is applied as a model for achieving non- parametric (or semi parametric) regression, it takes the advantage of the curve- fitting approach; once their internal parameters have been set to appropriate values, they are able to interpolate and even extrapolate the values that were not used in setting their structures. Unlike curve fitting approach, ANN is not limited by the choice of any particular mathematical function. A single Artificial Neural Network may therefore be used in a range of coastal data with varied sea condition.

The aim of this research work is to develop an artificial neural network for the modeling and prediction of water current magnitude and direction in the Commodore channel, Lagos State.

\section{MATERIALS AND METHOD}

\subsection{Study Area}

The Commodore channel which is also referred to as the Lagos harbour is a navigation channel in Lagos, Nigeria and is located near Beecroft and Wilmot point. The terrain elevation above sea level is 0 metre. It is situated on Latitude: $6^{0} 24^{\prime} 0^{\prime \prime}$ and Longitude: $3^{0}$ $24^{\prime} 0^{\prime \prime}$. It was dredged by British royal Engineers in 1908 for ships coming into the Lagos harbour which makes it one of the most important parts of the Lagos lagoon. The mouth of the inlet is bounded by three stone moles (east mole, west mole and west training mole). The Lagos harbour in Lagos Nigeria also serves as the only exit for the outflow of lagoon waters to the sea and inflow of sea waters resulting from tidal rise [23].

The Commodore Channel is a naturally protected basin equipped with docking and other facilities for the loading and unloading of cargo and usually with 
installations for the refuelling and repair of ships. Apart from oil depots sited along the shore of western parts of the Harbour coupled with the proliferation of urban and industrial establishments on the shore of the eastern part of the Harbour, the Harbour is used as a route to transport goods. Additionally, subsistence fishing takes place at some locations by local fishermen.

\subsection{Data Acquisition}

Current and tidal observations were carried out in this work. The Acoustic Doppler Current Profiler was attached to a vessel, which was connected to a workstation. The signal was sent to the workstation and the profile of the current across each transect was displayed on the screen of the workstation. A Tide Gauge was established in order to refer all the soundings to a common datum and tidal observation was carried out using an automatic tide gauge. The position of the tide gauge was appropriately chosen in such a manner that water will not dry off the staff at any time. The modelling phase of this research was done using MATLAB 2013. Data preparation for this work covered visual inspection and selection of data from an array of sample data available. Data used was carefully selected to ensure its reliability. While ANNs are tolerant to some degree of noise, they have difficulty identifying an underlying function in the presence of very high variability. A particular problem occurs in the presence of systematic errors which are likely to be incorporated into the approximating function since ANNs cannot distinguish between true trends and systematic errors.

Another issue that was considered during data preparation was the partitioning of the data into their functional parts and perspectives. This was needful because of the characteristic feature of the data such as:

- East and North component of the individual transect Current

- Resultant component of the individual transect

- Joint transect of both East and North component and resultant

- Tidal data corresponding to each transect The data was prepared in Microsoft Excel with extension .xls', although during programming the extension type was extended to include .xlsx' as it was later noticed that some versions of Microsoft excel do not have the former extension.
Other data processing stages were handled during the script- coding phase. These stages are:

- Processing of unknown input

- Representing the unknown target

Furthermore, every data presented to the network passed through the following processing rule:

$$
\begin{array}{r}
{[\mathrm{tn}, \mathrm{ts}]=\operatorname{mapminmax}(t) ;} \\
\text { net }=\text { train (net, pn, tn); }
\end{array}
$$

The original network inputs and targets are given in the matrices $p$ and $t$. The normalized inputs and targets $\mathrm{pn}$ and th that were returned will all fall in the interval $[-1,1]$. The structures ps and ts contain the settings. In this case, the minimum and maximum values of the original inputs and targets. After the network has been trained, the ps settings can be used to transform any future inputs that are applied to the network. They effectively become a part of the network, just like the network weights and biases.

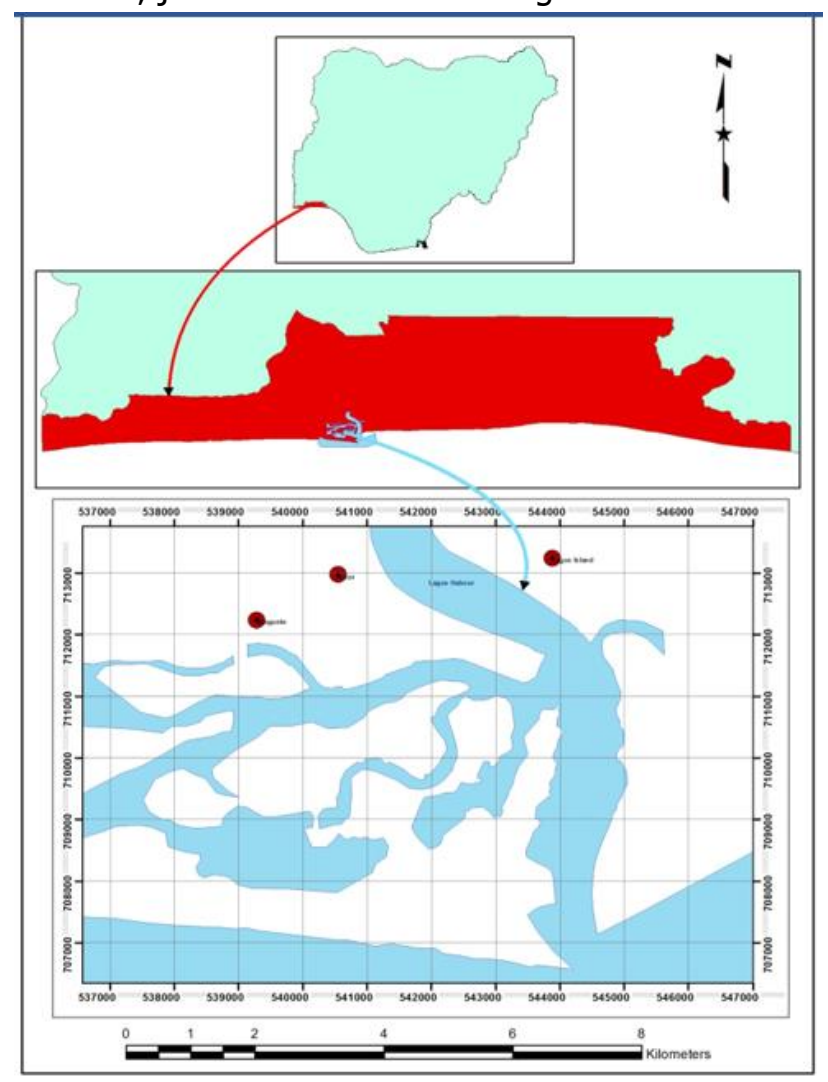

Figure 1: Lagos Harbour area

\subsubsection{Network Creation}

Network creation involves creating a subroutine that specifies number of layers, neuron in each layer, and a chosen learning or training rule. A call back function was developed to call a function which created a feed forward backpropagation network in a matlab environment.

The backpropagation network function is of the form, 
net $=\operatorname{NEWFF}(\mathrm{P}, \mathrm{T}, \mathrm{S}, \mathrm{TF}, \mathrm{BTF}, \mathrm{PF}, \mathrm{IPF}, \mathrm{OPF}, \mathrm{DDF})$

Where

$P$ is matrix of input vectors.

$\mathrm{T}$ is matrix of target vectors.

$\mathrm{S}$ is sizes of hidden layers (Output layer size is determined from $\mathrm{T}$ ).

TF is Transfer function.

BTF is Backprop network training function (trainlm).

$\mathrm{PF}$ is Performance function (mse).

IPF is Row cell array of input processing functions

\{'fix unknowns','remconstantrows','mapminmax'\}.

OPF is Row cell array of output processing functions \{'remconstantrows','mapminmax'\}.

DDF is Data division function ( divides the data in the ratio of ' $6: 2: 2$ '; and returns an $\mathrm{N}$ layer feed-forward backprop network.

\subsubsection{Data division for Training, Validation and Testing}

Input $/$ Target dataset $=100 \%$

Validation $=20 \%$

Training $=60 \%$

Test $=20 \%$

The dataset presented to the model was randomly divided into 3 sets in the ratio of '60:20:20', for training, Validation, and testing respectively.

This division follows a predefined division rule 'divider and' specified during network creation phase

\subsubsection{Network Training}

Network training forms the central core activity in all phases of neural Network modelling. The training process requires a set of examples of proper network behavior, that is network inputs $\mathrm{p}$ (current and water level data designated as input) and target outputs $t$ (current designated as output). During training, the weights and biases of the network are iteratively adjusted to minimize the network performance function. This was done using the standard Levernberg-Marquardt training process.

The Levernberg-Marquardt training process can be illustrated in the following pseudo-codes:

1. Initialise the weights and parameter $\mu(\mu=.01)$ is appropriate

2. Compute the sum of the squared errors over all inputs $F(w)$

3. Solve (2) to obtain the increment of weights $\Delta w$.

4. Recompute the sum of squared errors $F(w)$. Using $w+\Delta w$ as the trial $w$, and judge:

If trial $F(w)<F(w)$ in step 2 then $w=w+\Delta w$ and

$$
\mu=\mu . \beta,(\text { for } \beta=1)
$$

Go back to step 2

ELSE

$$
\mu=\frac{\mu}{\beta}
$$

END IF

$\mu$ is the learning rate which is to be updated using the $\beta$. In particular, $\mu$ is multiplied by decay rate $\beta \quad(0<$ $\beta<1$ ) whenever $F(w)$ decreases, whereas $\mu$ is divided by $\beta$ whenever $F(w)$ increases in a new step The training subroutine for reading the water level data into training module via the created network was developed. This subroutine reads prepared water level data from Microsoft excel into the model for training.

A function which handles the training is expressed as:

$$
\text { [net, } \operatorname{tr}]=\text { TRAIN }(\mathrm{NET}, \mathrm{P}, \mathrm{T}, \mathrm{Pi}, \mathrm{Ai})
$$

Where

TRAIN trains a network NET according to NET.trainFcn and NET.trainParam.

TRAIN (NET, P, T, )

NET is Network.

$P$ is Network inputs (Water level data designated as input).

$\mathrm{T}$ is Network targets (Water level data designated as target).

Net takes a new trained network (This is the network that shall be used for prediction)

tr is Training report (epoch and performance)

\subsubsection{Performance Evaluation of the Trained Network}

After each instant of training, the performance of the trained network is tested with two performance functions:

- Regression Analysis (R)

- Mean Square Error (mse)

The regression analysis gives the measure of how well the variation in the output is explained by the targets. If this number is equal to 1 , then there is perfect correlation between targets and outputs. However, the result is not usually 1 as input cannot be equal to target. The Graphical User Inteface designed in this work was done in such a way that the user is allowed to check for this error with great ease before adopting the network. The subroutine which handled the regression analysis is expressed as: 


$$
[m, b, r]=\operatorname{postreg}(Y, T)
$$

\section{Description}

POSTREG postprocesses the network training set by performing a linear regression between one element of the network response and the corresponding target.

POSTREG $(P, T)$ takes these inputs, $Y$-network outputs and one element of the network output.

$T$ is array of targets. One element of the target vector and returns and plots, $M, B, R$

$M$ is Slope of the linear regression.

$B$ is $Y$ intercept of the linear regression.

$\mathrm{R}$ is Regression $\mathrm{R}$-value. $\mathrm{R}=1$ means perfect correlation.

Besides the regression analysis, the Mean square error function was also used to evaluate the performance of the model. The Mean Square Error (mse) function used in the model is mathematically expressed as :

$$
F=\frac{1}{n} \sum_{i=1}^{n}\left(e^{i}\right)^{2}
$$

where $\mathrm{F}=$ performance function, $n=$ the total number of samples, $i=$ counter or iterative term, $\mathrm{e}=$ error (difference between the target and output). The various performance indices achieved during the training, validation, and testing are reported in the result analysis section.

Once the performance index was satisfactory the network was ready to be deployed for simulation and subsequent prediction. For each training instant, the threshold values which give good predictions are 0.8 and 0.05 for Regression and MSE respectively.

The whole of this narrative was developed into application using MATLAB programming Language.

\subsection{Network Building}

Network building phase in ANNs modelling involves specification of the number of hidden layers, the neurons in each layer, transfer function in each layer, weight/bias learning function, and performance function. [24].

After extensive review of several ANNs Architecture with their attendant advantages and challenges, a standard feed forward back propagation network with a nonlinear differentiable log-sigmoid transfer function in the hidden layer was adopted for this work. A schematic diagram of the model architecture is shown in Figure 2.

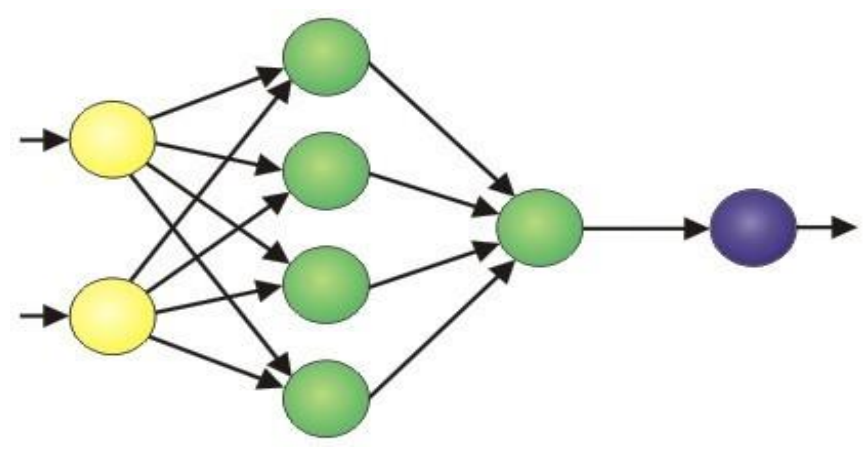

Input layer (current and tide) hidden layer transfer function output (current)

Figure 2: Schematic diagram of the ANNs model used in this work

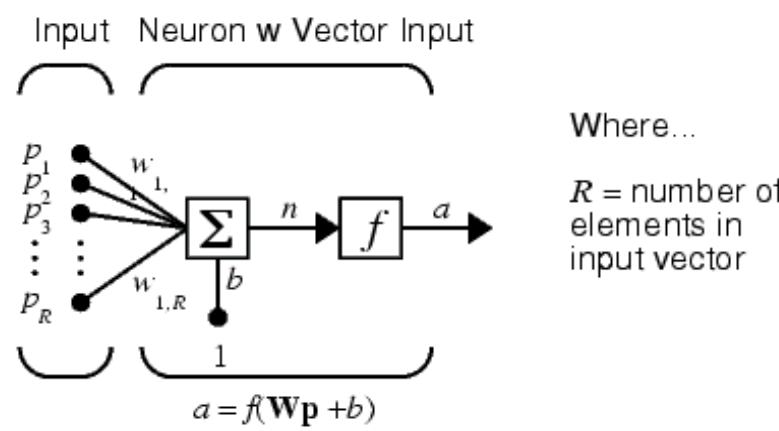

Figure 3: Neural networks Mathematical model

From Figure 3 above, $a$ is the output, $f$ is the transfer function, $\mathrm{W}$ is the weight, $\mathrm{b}$ is the bias, $\mathrm{P}$ is the Input and $n$ is the neuron. The neuron has a bias $b$, which is summed with the weighted inputs to form the netinput $\mathrm{n}$.

$$
n=W_{1} 1 P_{1}+W_{1} 2 P_{2}+\cdots W_{1} R P_{R}+b
$$

The expression in Equation (10) can be written in matrix form:

$$
n=W P+b
$$

where the matrix $W$ for the single neuron case has only one row.

Now the neuron output can be written as:

$$
a=f(W P+b)
$$

\section{Data division for training, validation and testing}

$\begin{array}{lll}\text { Input /Target dataset } & = & 100 \% \\ \text { Validation } & = & 20 \% \\ \text { Training } & = & 60 \% \\ \text { Test } & = & 20 \%\end{array}$

The dataset presented to the model is randomly divided into 3 sets in the ratio of ' $60: 20: 20$ ', for training, Validation, and testing respectively. For each instant of training, water current data presented as 
input to the model is divided into 3 parts as shown in Figure 3 above. This division follows a predefined division rule specified during the network creation phase.

\subsection{Adoption of Training Instant Using Regression and Mean Square Margin}

In order to adopt an instant of training for simulation and subsequent prediction, the training, validation, and model testing are subjected to regression analysis ( $R$ ) and mean square error (mse) analysis. The result of this analysis gives the basis for accepting or ignoring a training instant.

The GUI developed during this study plots the results of regression, and mse at the prompt of the performance button. The sample regression and mse plots generated during the training of dataset for one of the transect of current used in this study are shown in Figure 4.

\subsection{Current Prediction Using Seven Transects (Regional Case)}

Current and water level data observed in January, 2014 for the Commodore channel was divided into seven transects. Each part consists of one row of observation. The seven transects were used for training, that is the corresponding water level of the Commodore channel at the time of observation was used as input and the corresponding current data of the commodore channel data was used as target. This is a typical case of Regional Neural Network Prediction. The results of the prediction with the associated statistical analysis are shown in Figures 5 to 16 and Tables 3 to 5 respectively.
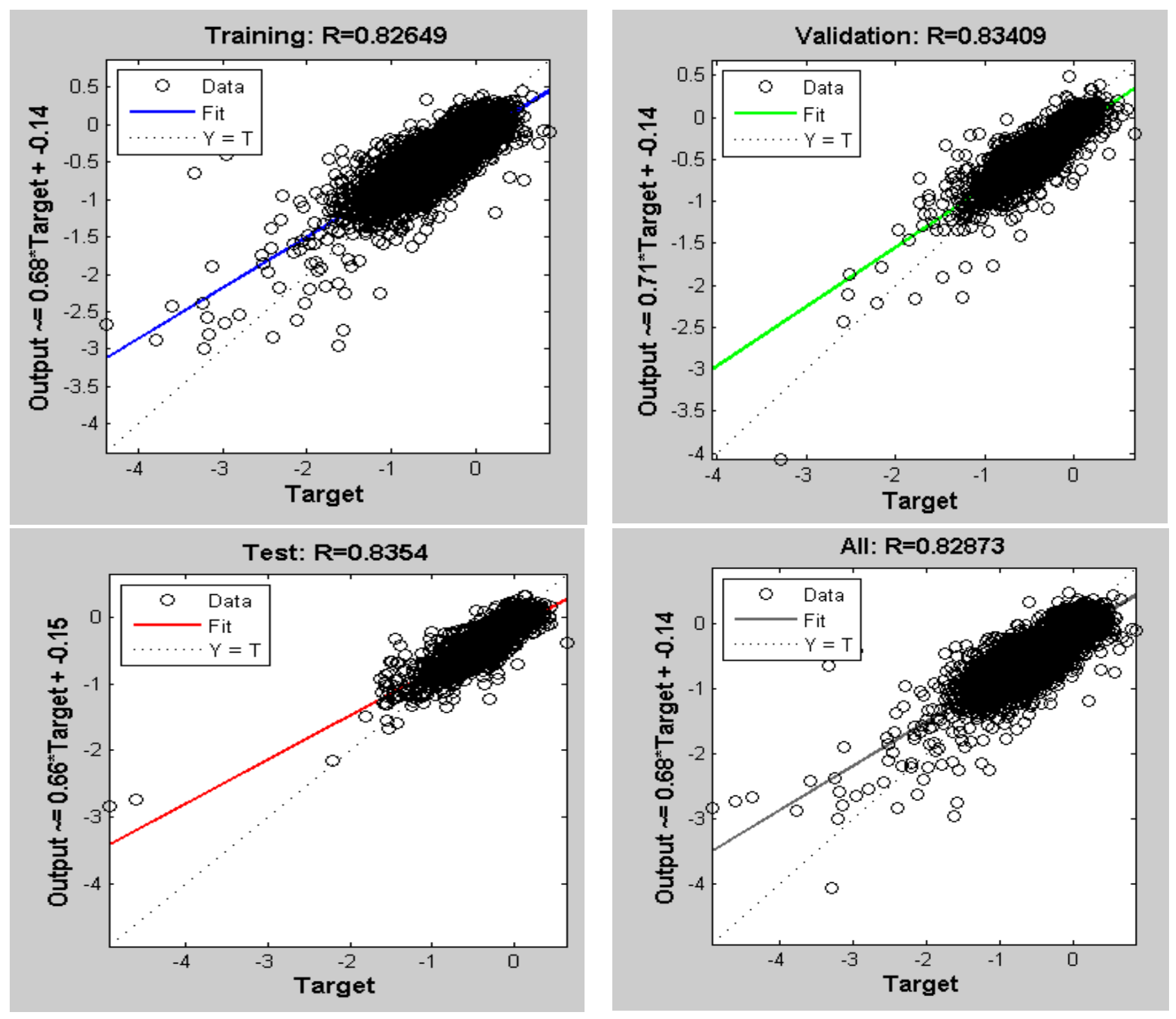

Figure 4: A plot of Regression for Training, Validation and Testing 
Table 1 Coordinates of some Observation Points

\begin{tabular}{lllllll}
\hline \multirow{3}{*}{ Transect 1 } & Easting $(\mathrm{m})$ & 544234.8 & 544244.8 & 544254.7 & 544264.7 & 544274.7 \\
& Northing $(\mathrm{m})$ & 707439.0 & 707439.8 & 707440.6 & 707441.5 & 707442.3 \\
& Distance $(\mathrm{m})$ & 10 & 20 & 30 & 40 & 50 \\
\hline \multirow{3}{*}{ Transect 2 } & Easting $(\mathrm{m})$ & 544474.0 & 544483.9 & 544493.9 & 544503.9 & 544513.8 \\
& Northing $(\mathrm{m})$ & 707458.7 & 707459.5 & 707460.3 & 707461.1 & 707461.9 \\
& Distance $(\mathrm{m})$ & 250 & 260 & 270 & 280 & 290 \\
\hline \multirow{3}{*}{ Transect 3 } & Easting $(\mathrm{m})$ & 544723.1 & 544733.0 & 544743.0 & 544753.0 & 544762.9 \\
& Northing $(\mathrm{m})$ & 707480 & 707480.8 & 707481.6 & 707482.4 & 707483.2 \\
& Distance $(\mathrm{m})$ & 500 & 510 & 520 & 530 & 540 \\
\hline \multirow{2}{*}{ Transect 4 } & Easting & 544972.2 & 544982.2 & 544992.2 & 545002.1 & 545012.1 \\
& Northing $(\mathrm{m})$ & 707500.3 & 707501.2 & 707502 & 707502.8 & 707503.6 \\
& Distance $(\mathrm{m})$ & 750 & 760 & 770 & 780 & 790 \\
\hline
\end{tabular}

The Acoustic Doppler Current Profiler (ADCP) acquired data at some depths along each of the seven transects. Some of the distances and corresponding depths at which current data were acquired are:

i. At Om distance, the Acoustic Doppler Current Profiler (ADCP) acquired current data at six depths, these depths are $2.43 \mathrm{~m}, 2.93 \mathrm{~m}$, $3.43 \mathrm{~m}, 3.93 \mathrm{~m}, 4.43 \mathrm{~m}$ and $4.93 \mathrm{~m}$

ii. At $10 \mathrm{~m}$ distance, the ADCP acquired current data at six depths, these depths are $2.43 \mathrm{~m}$, $2.93 \mathrm{~m}, 3.43 \mathrm{~m}, 3.93 \mathrm{~m}, 4.43 \mathrm{~m}$ and $4.93 \mathrm{~m}$

iii. At $240 \mathrm{~m}$ distance, the equipment acquired current data at thirteen depths, these depths are $0.93,1.43 \mathrm{~m}, 1.93 \mathrm{~m}, 2.43 \mathrm{~m}, 2.93 \mathrm{~m}$, $3.43 \mathrm{~m}, 3.93 \mathrm{~m}, 4.34 \mathrm{~m}, 4.93 \mathrm{~m}, 5.93 \mathrm{~m}, 6.43 \mathrm{~m}$, $6.93 \mathrm{~m}$ and $7.43 \mathrm{~m}$

iv. At $970 \mathrm{~m}$ at the equipment acquired current data at fifteen depths, these depths are 0.93 , $1.43 \mathrm{~m}, 1.93 \mathrm{~m}, 2.43 \mathrm{~m}, 2.93 \mathrm{~m}, 3.43 \mathrm{~m}, 3.93 \mathrm{~m}$, $4.34 \mathrm{~m}, 4.93 \mathrm{~m}, 5.43 \mathrm{~m}, 5.93 \mathrm{~m}, 6.43 \mathrm{~m}, 6.93 \mathrm{~m}$, $7.43 \mathrm{~m}$ and 7.93

\section{RESULTS AND ANALYSIS}

\subsection{Results}

Table 2 shows a section of raw data acquired by ADCP at $10 \mathrm{~m}$ distance. The graphs below show the results of the observed, predicted and residual currents for different depths along transects 1 to 6 .

\subsection{Analysis of Results}

Tables 3 to 5 show statistics of predictions using the developed model.
Table 2: $A$ section of raw data acquired by ADCP at $10 \mathrm{~m}$ Distance

\begin{tabular}{lllll}
\hline \multicolumn{5}{c}{ Commodore Channel Transect 1: 10m } \\
\hline Depth & \multicolumn{4}{c}{ Velocity $(\mathrm{m} / \mathrm{s})$} \\
\hline$[\mathrm{m}]$ & East & North & Error & Current \\
\hline 2.43 & 0.422 & 0.35 & 0.187 & 0.307 \\
2.93 & 0.538 & 0.237 & 0.135 & 0.094 \\
3.43 & 0.391 & 0.241 & 0.01 & 0.225 \\
3.93 & 0.236 & 0.238 & 0.055 & 0.201 \\
4.43 & 0.358 & 0.362 & 0.143 & 0.307 \\
4.93 & 0.213 & 0.418 & 0.125 & 0.326 \\
\hline
\end{tabular}

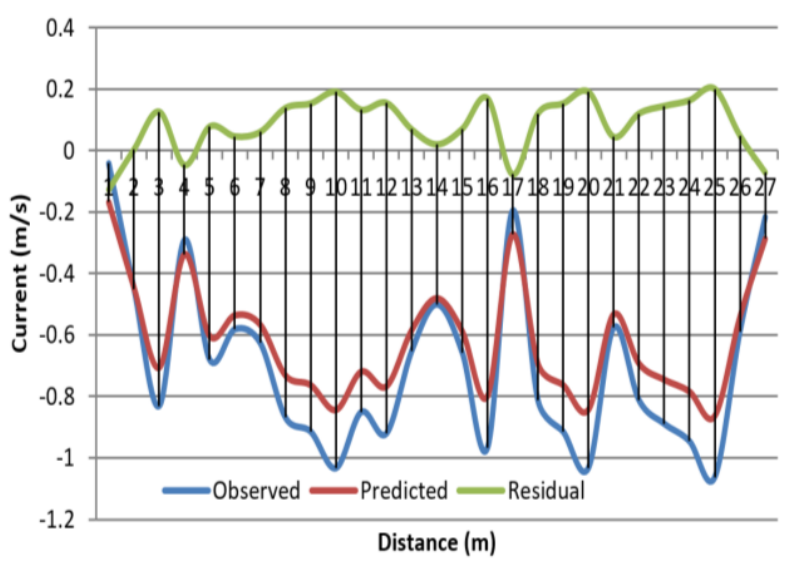

Figure 5: Distribution of Observed, Predicted and Residual Currents at depth $1.93 \mathrm{~m}$ (Transect 1)

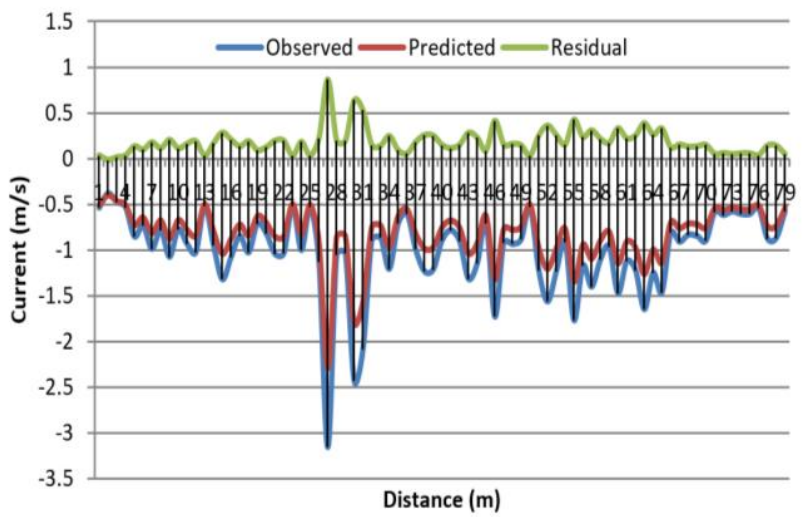

Figure 6: Distribution of Observed, Predicted and Residual Currents at depth 6.93m (Transect 1) 


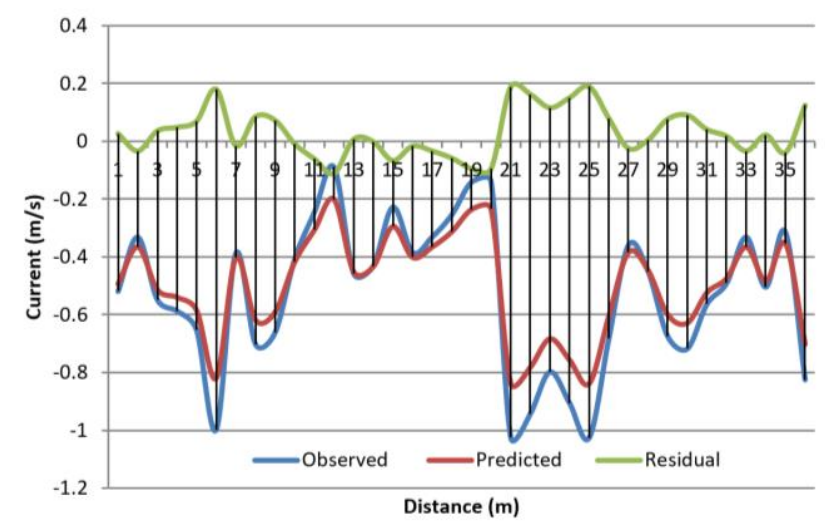

Figure 7: Distribution of Observed, Predicted and Residual Currents at depth 1.93m (Transect 2)

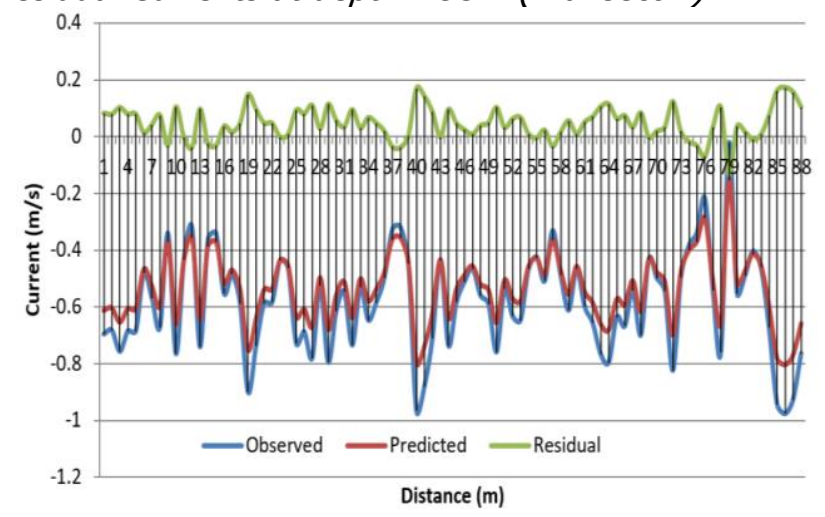

Figure 8: Distribution of Observed, Predicted and Residual Currents at depth 6.93m (Transect 2)

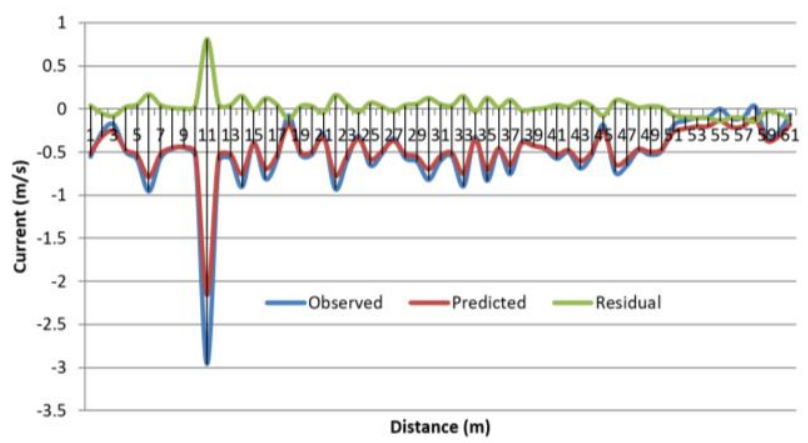

Figure 9: Distribution of Observed, Predicted and Residual Currents at depth 1.93m (Transect 3)

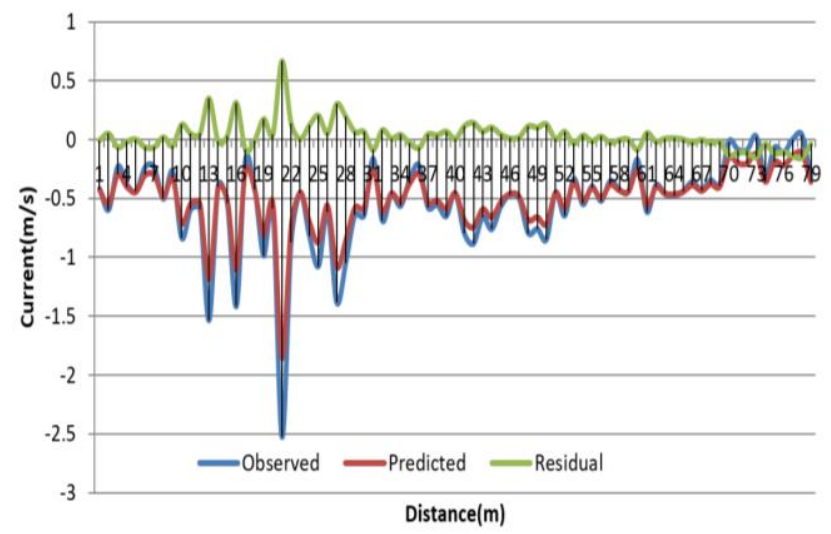

Figure 10: Distribution of Observed, Predicted and Residual Currents at depth 6.93m (Transect 3)

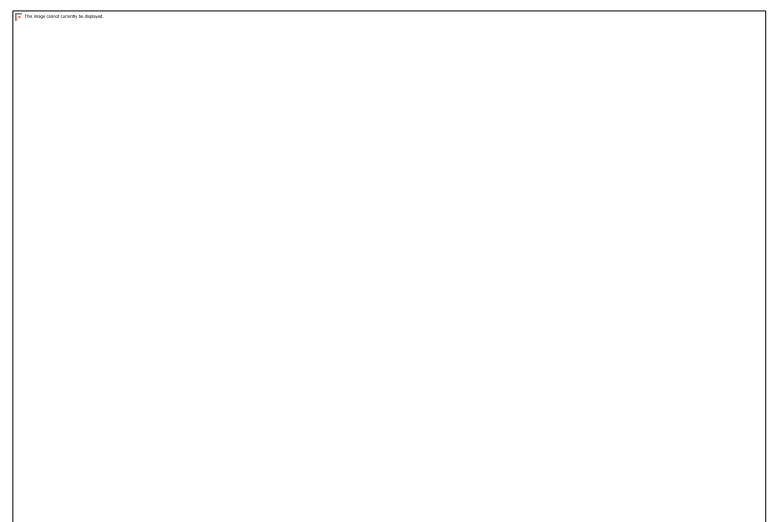

Figure 11: Distribution of Observed, Predicted and Residual Currents at depth 1.93m (Transect 4)

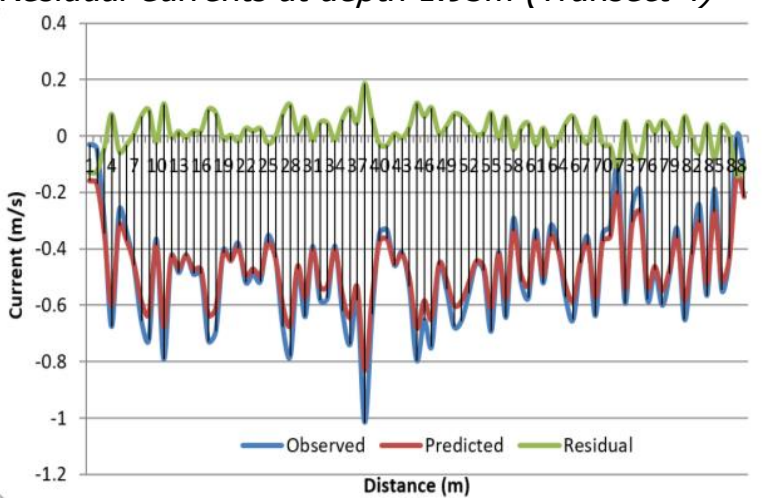

Figure 12: Distribution of Observed, Predicted and Residual Currents at depth 6.93m (Transect 4)

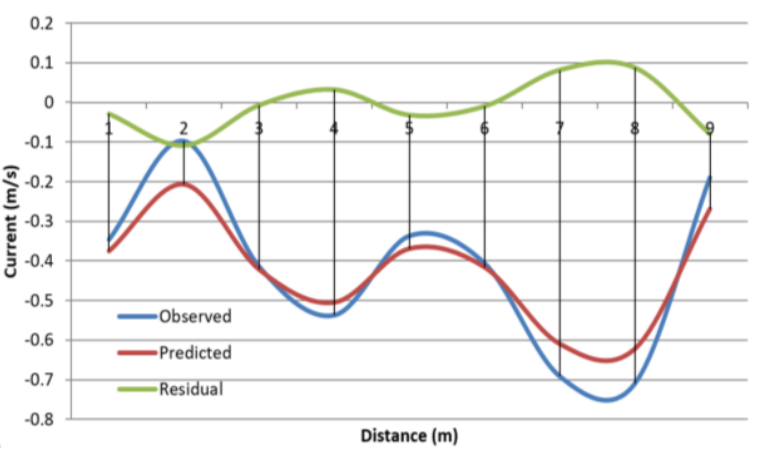

Figure 13: Distribution of Observed, Predicted and Residual Currents at depth $1.93 \mathrm{~m}$ (Transect 5)

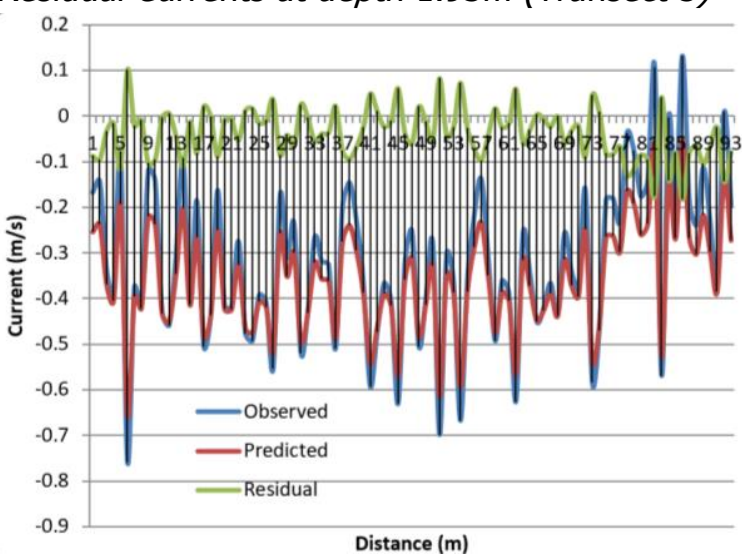

Figure 14: Distribution of Observed, Predicted and Residual Currents at depth 6.93m (Transect 5) 


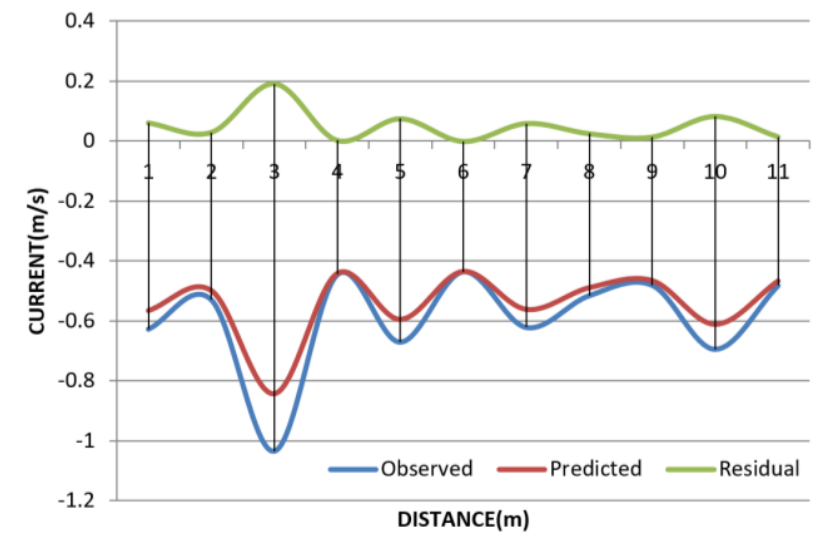

Figure 15: Distribution of Observed, Predicted and Residual Currents at depth 1.93m (Transect 6)

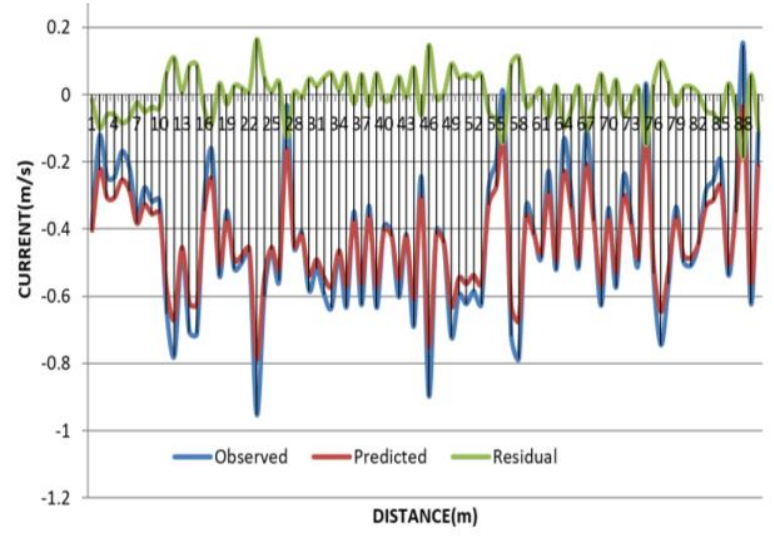

Figure 16: Distribution of Observed, Predicted and Residual Currents at depth 6.93m (Transect 6)

Table 3: Statistics of prediction for Transects 1-6 using Depth and Current as Input and Current as Target

\begin{tabular}{ccccc}
\hline $\begin{array}{c}\text { Epoch } \\
\text { (No of iterations) }\end{array}$ & $\begin{array}{c}\text { Time } \\
(\mathrm{Sec})\end{array}$ & $\begin{array}{c}\text { Performance } \\
(\mathrm{mse})\end{array}$ & Gradient & Validation Check \\
\hline \hline 13 & 3 & 0.0430 & 0.0822 & 6 \\
\hline \hline Training & Regression & \\
0.8366 & Validation & Test \\
\hline
\end{tabular}

Table 4: Statistics of prediction for Transects 1-6 using Current as Input and Current as Target

\begin{tabular}{ccccc}
\hline $\begin{array}{c}\text { Epoch } \\
\text { (No of iterations) }\end{array}$ & $\begin{array}{c}\text { Time } \\
(\mathrm{Sec})\end{array}$ & $\begin{array}{c}\text { Performance } \\
(\mathrm{mse})\end{array}$ & Gradient & Validation Check \\
\hline 20 & 91 & 0.0461 & 0.0160 & 6 \\
\hline \hline Training & Regression & & \\
0.82649 & Validation & & Test \\
\hline
\end{tabular}

Table 5: Statistics of prediction for Transects 1-7 using depth as input and Current as Target

\begin{tabular}{ccccc}
\hline $\begin{array}{c}\text { Epoch } \\
\text { (No of iterations) }\end{array}$ & $\begin{array}{c}\text { Time } \\
(\mathrm{Sec})\end{array}$ & $\begin{array}{c}\text { Performance } \\
(\mathrm{mse})\end{array}$ & Gradient & Validation Check \\
\hline 11 & 2 & 0.0448 & 0.0419 & 6 \\
\hline \hline Training & Regression & & Test \\
0.81946 & Validation & & 0.80926 \\
\hline
\end{tabular}

\subsection{Discussion of Results}

Modelling of Hydrodynamic phenomenon with Artificial Neural Network has gained increasing attention. The reason for this resurgence of interest is probably due to ANNs being a new-comer modelling tool in Hydro informatics.

Two sets of data, the input and target were subjected to training with varying network parameters until a satisfactory model with some desired measure of accuracy was achieved. The model was successfully tested in the case study using data from the
Commodore Channel. Using short-term data sets, the model was trained, validated and tested using a ratio of 6: 2: 2 for training, validation and testing respectively. The Performance index ranges from 0.043 to 0.0448 in terms of Mean Square Error (MSE) and 0.80 to 0.83 in terms of correlation coefficient (Rvalue). From this work, current data along the coastal environment can be easily forecasted.

Various renowned bodies and governments of the world are voting enormous resources towards developing ANNs for Coastal Phenomena modelling 
and water current prediction seems to be taking the lead in this expedition

\section{CONCLUSION AND RECOMMENDATION}

\subsection{Conclusion}

Water current statistics is very essential for coastal engineering and development. No substantial coastal development work is complete without serious recourse to water current data. However, acquiring this data can be rigorous. It was upon this basis that this research work was embarked on.

A Neural Network for Water Current modelling and prediction has been successfully developed in this study of water current predictions at the commodore channel. The model inputs are time series water current data. The model requires the input of time series water current data with a corresponding time series water level data of the commodore channel, whose water current is to be predicted. The two sets of data, the input and target were subjected to training with varying network parameters until a satisfactory model with some desired measure of accuracy was achieved. The model was successfully tested in the case study using data from the Commodore Channel. Using short-term data sets, the model was trained, validated and tested using a ratio of 6: 2: 2 for training, validation and testing respectively. The Performance index ranges from 0.043 to 0.0448 in terms of Mean Square Error (MSE) and 0.80 to 0.83 in terms of correlation coefficient ( $R$-value). Given this plausible performance, it is not out of place to infer that the Neural Networks Water Current Model developed in this study is a practical tool for serving the following needs:

i. Prediction of long-term historic water current data at a station of interest or remote station using regional approach.

ii. Effective long-term water current data for the study of hydrodynamics.

iii. A reduction in the cost of procuring expensive water current monitoring instruments.

\subsection{Recommendation}

The following recommendations are made as a result of this work:

i. Unavailability of data has hindered model development and application. Individuals and Institutions in charge of data repository should willingly make this data available for genuine use. It is interesting to note that modelling of some environmental phenomenon which is data driven can help in solving some of our major environmental challenges like flooding and erosion.

ii. There are recent innovations on combination of neural network and harmonic analysis for improved Water Current analysis and prediction covering long periods. This development can be practically researched to assess the validity of the proposal thereby contributing to the body of knowledge on coastal study.

iii. Government and non-governmental agencies should collaborate with tertiary institutions to broaden knowledge in the field of Artificial Neural Network.

\section{REFERENCES}

[1] Taylor, Jack. "What Are Water Currents?" Sciencing, http://sciencing.com/water-currents8042449.html. Accessed on April 25, 2017

[2] Dobson, F., L. Hasse and Davids, R. Air-Sea Interaction Instruments and methods. Plenum Press, New York, 1980, 801pp.

[3] Vella, M., Ses, S., and Kadir, M., "Preliminary Ocean Tide Model Inferred by Satellite Altimetry for a Test Section of the Asean Region". 22nd Asian Conference on Remote Sensing, 5-9 November, 2001, Singapore.

[4] Mueller, D.S., and Wagner, C.R., Measuring discharge with acoustic Doppler current profilers from a moving boat: U.S. Geological Survey Techniques and Methods, 2009 3A-22, 72 p. http://pubs.water.usgs.gov/tm3a22). Accessed in 2014.

[5] National Oceanic and Atmospheric Administration (NOAA). http://oceanexplorer.noaa.gov/ education/kits/currents/08affect.html. Accessed in 2017

[6] Bose N K and Liang P. Neural Network Fundamentals with Graphs, Algorithms and Applications. Tata McGraw-Hill, 1998, pp.478.

[7] Nishiyama, M., and Filion, Y. "Forecasting Water Main Failure using Artificial Neural Network and Generalized Linear Models". World Environmental and Water Resource Congress 2013: 15th Annual Water Distribution System Analysis Symposium.

[8] Hagan, M.T., Demuth, H. and Beale, M. Neural Network Design. PWS Publishing Company, Boston, MA, 1995. 
[9] Kowaliw T., Bredeche N., Chevallier S. and Doursat R. "Growing Adaptive Machines, Studies in Computational Intelligence", Springer, 2014.

[10] Lee, T. L. "Neural network prediction of a storm surge", Elsevier J Ocean Engineering, 33, 2006, pp 483-494.

[11] Mandal, S., Patil, G., Manjunatha, Y.R. and Hegde, A.V. "Application of Neural Networks in Coastal Engineering - an Overview", 12th International Conference of International Association for Computer Methods and Advances in Geomechanics (IACMAG) 1-6 October, 2008 Goa, India.

[2] Aichouri, I., Hani, A., Bougherira, N., Djabi, L., Chaffai, H., and Lallahem, S. "River flow model using artificial neural networks", International Conference on Technologies and Materials for Renewable Energy, Environment and Sustainability, 2015.

[13] Riad S., Mania J., Bouchaou L. and Najjar Y. "Rainfall-Runoff Model Using an Artificial Neural Network Approach", Mathematical and Computer Modelling 40 (2004), pp 839-846.

[14] Lallahem S., Mania J., Hani A. and Najjar Y. "On the use of neural networks to evaluate groundwater levels in fractured media", Journal of Hydrology 307; 2005. pp. 92-111.

[15] Smith I. and Eli R.N. "Neural-network models of rainfall-runoff process", Journal of Water Resources Planning and Management, 121 (6), 1995, 499-508.

[16] Maier H.R. and Dandy G.C. "The use of artificial neural network for the prediction of quality water parameters", Water Resources Research 32 (4), 1996, pp 1013-1022.
[17] Sudheer K.P., Gosain A.K., Mohana Rangan D. and Saheb S.M. "Modelling evaporation using an artificial neural network algorithm", Hydrol. Process. 16, 2002, pp 3189-3202.

[18] Minns A.W. and Hall M.J. "Artificial neural networks as rainfall-runoff models", Hydrological Sciences Journal 41 (3), 1995, pp 399-418.

[19] Wei Y., Xu W., Fan Y. and Tasi H.T. "Artificial neural network based predictive method for flood disaster", Computers \& Industrial Engineering, 42, 2002, pp 383-390.

[20] Hu T.S., Lam K.C. and Ng S.T. "River flow time series prediction with a range-dependent neural network". Hydrological Science Journal, 46 (5), 2001.p. 729-745.

[21] Lippmann R.P. "An introduction to computing with neural nets", IEEE ASSP Magazine, 1987, pp 4-22.

[22] Badejo, O.T. and Udoudo, D. "Modelling and Prediction of Water Level for a Coastal Zone Using Artificial Neural Networks", International Journal of Computational Engineering Research, 2250 - 3005, Vol. 04 , Issue 6, June 2014.

[23] Onyema, I.C., Nwankwo, D.I. and K.O. Owolabi, K.O. "Temporal and Spatial Changes in the Phytoplankton Dynamics at the Tarkwa-Bay Jetty In Relation to Environmental Characteristics". Ecology, Environment and Conservation, Vol. 14, Number4, 2008. pp 1-9.

[24] Andrews R., Diederich J. and Tickle A. "Survey and Critique of Techniques for Extracting Rules from Trained Artificial Neural Networks". Knowledge Based Systems, Vol. 8, Number 6, 1998, pp. 373- 389. 